DOI: $10.17516 / 1997-1370-0760$

УДК 316.73

\title{
Historiography of Studies of Ethnocultural Dynamics in the Republic of Khakasia
}

\author{
Ksenia A. Degtyarenko*, Natalia N. Seredkina \\ and Anna A. Shpak \\ Siberian Federal University \\ Russian Federation, Krasnoyarsk
}

Received 18.03.2021, received in revised form 08.04.2021, accepted 21.05.2021

\begin{abstract}
The article is a chronologically systematized review of the sources of the Soviet and modern periods for the study of ethnocultural dynamics in the Republic of Khakassia. A separate block is devoted to studies of modern ethnic processes at the turn of the $20^{\text {th }}-21^{\text {st }}$ centuries. The article presents the specifics of the study of the ethnocultural dynamics of the capital and regional research centers. Attention to ethnic processes in the republic is fixed from the standpoint of history, ethnopsychology, sociology, cultural studies, and anthropology. The main problems and trends in the study of ethnic processes in the region are considered. Priority research areas related to the study of ethnic identity and the specifics of its formation are highlighted as the features of modern scientific research within the framework of this issue in the context of modern processes of globalization and transformation. Particular attention is paid to the analysis of interethnic relations and migration processes taking place in the Republic of Khakassia.
\end{abstract}

Keywords: ethnocultural dynamics, Khakassia, Khakass ethnos, indigenous and small peoples of Khakassia, ethnic identity, globalization.

The research was funded by RFBR, Krasnoyarsk Territory and Krasnoyarsk Regional Fund of Science, project number 20-49-240001.

Research area: culturology.

Citation: Degtyarenko, K.A., Seredkina, N.N., Shpak, A.A. (2021). Historiography of studies of ethnocultural dynamics in the Republic of Khakasia. J. Sib. Fed. Univ. Humanit. Soc. Sci., 14(6), 782 796. DOI: $10.17516 / 1997-1370-0760$.

(C) Siberian Federal University. All rights reserved

* Corresponding author E-mail address: akseniya.krupkina@mail.ru

ORCID: 0000-0002-6398-0259 (Degtyarenko); 0000-0002-9248-8810 (Seredkina); 0000-0002-2948-8762 (Shpak) 


\title{
Историография исследований этнокультурной динамики в Республике Хакасия
}

\author{
К.А.Дептяенко, Н.Н. Середкина, А.А. Шпак \\ Сибирский федеральный университет \\ Российская Федерачия, Красноярск
}

\begin{abstract}
Аннотация. Статья представляет собой хронологически систематизированный обзор источников советского и современного периодов по исследованию этнокультурной динамики в Республике Хакасия. Отдельным блоком выделены исследования современных этнических процессов рубежа XX-XXI вв. Изложена специфика изучения этнокультурной динамики столичных и региональных научноисследовательских центров. Фиксируется внимание к этническим процессам в республике с позиции истории, этнопсихологии, социологии, культурологии, антропологии. Рассматриваются основные проблемы и направления в изучении этнических процессов на территории региона. В качестве особенностей современных научных исследований в рамках данного вопроса выделяются приоритетные направления, связанные с изучением этнической идентичности и спецификой ее формирования в контексте современных процессов глобализации и трансформации. Особое внимание уделяется анализу межэтнических отношений и миграционных процессов, протекающих в Республике Хакасия.
\end{abstract}

Ключевые слова: этнокультурная динамика, Хакасия, хакасский этнос, коренные и малочисленные народы Хакасии, этническая идентичность, глобализация.

Исследование выполнено при финансовой поддержке РФФИ, Правительства Красноярского края и Красноярского краевого фонда науки в рамках научного проекта № 20-49-240001.

Научная специальность: 24.00 .00 - культурология.

Аналитический обзор научных источников представляет собой историографию исследований этнокультурной динамики в Республике Хакасия, начиная с образования СССР и заканчивая современными исследованиями XXI в. Рассмотрение основных проблем и направлений в изучении этнических процессов на территории республики с разнообразных научных позиций (истории, этнопсихологии, социологии, культурологии, антропологии) позволяет выявить некоторые закономерности этнокультурной динамики региона. Это в свою очередь подчеркивает особую актуальность данного исследования. Современные процессы глобализации и трансформации, затрагивающие разные сферы жизни хакасского народа, процессы межкультур- ного взаимодействия обостряют вопросы этнического самосознания, этнической идентификации и самоидентификации коренных народов. Приоритетными среди современных научных исследований становятся направления, связанные с изучением специфики актуальных этнокультурных процессов и механизмов формирования этнокультурной идентичности.

\section{Обзор научной литературы советского периода (до 1991 г.)}

Историография научной литературы периода СССР затрагивает период с 1922 по 1991 г. и включает в себя достаточно обширный материал.

В качестве особенностей рассматриваемого исторического периода следует ука- 
зать на изменение в историографии с точки зрения методологии и концептуального начала. Так как исследования в советский период опираются на марксизм в качестве научного метода, это в некоторой степени ограничивает развитие научной мысли. Таким образом, анализ духовной жизни народов в связи с историческим догматами теряет некоторое самостоятельное значение. Также в начале становления советской власти изучение этноса Хакасии происходит преимущественно при музеях в Ленинграде, Новосибирске, Томске, что указывает на достаточно узкую сферу деятельности региональных научных центров по отношению к столичным.

В 1930-1950-е гг. появляются новые местные центры изучения хакасского этноca, в данном случае возникает региональный научно-исследовательский центр в Хакасии (Хакасский научно-исследовательский институт языка, литературы и истории). Работа по этнографии хакасского народа ведется по-прежнему и в столичных центрах, Ленинграде и Москве. Прежние центры становятся более обширными, и к ним добавляются города: Красноярск, ГорноАлтайск, Абакан, Минусинск.

Можно разделить исследования на такие категории, как изучение родового строя этноса, родоплеменной состав этноса, происхождение этноса, лингвистические процессы, искусство, религия, культура этноса, исследования по физической антропологии и археологические исследования.

При описании историографии стоит отметить, что большую часть исследований представляют работы, связанные с хакасским этносом, меньшую - с шорцами.

Говоря о развитии изучения этносов, проживающих на территории Республики Хакасия, стоит отметить исследователя Н.Ф. Катанова, внесшего существенный вклад в дальнейшее развитие советской науки в области этнографии, фольклора и лингвистических процессов тюркских языков. Множество работ посвящено именно фольклору хакасского этноса.

В группу, занимающуюся семантикой хакасского языка, можно отнести таких ис- следователей, как Н. Г. Доможаков, Н. А. Баскаков, Г.И. Донидзе, Г.Ф. Бабушкин, В. Г. Карпов, М.И. Боргояков, А.И. Грекул, Д.И. Чанков, В. В. Бартольд.

Н.Г. Доможаков (Domozhakov, 1949) в научных трудах раскрывает семантику хакасского языка, изучает диалекты и синтаксис языка. В то же время и не обходится в его трудах без тщательного изучения фольклора, проведенного в различных экспедициях. Необходимо отметить, что Н.Г. Доможаков также был инициатором создания и первым директором Хакасского научно-исследовательского института языка, литературы и истории.

Исследования родового строя Хакасии отражено в работах Ю.А. Шибаевой, К. М. Патачакова, С. А. Токарева.

Ю.А. Шибаева рассматривает пережитки родового строя у хакасов и классифицирует систему родства хакасов в целом (Shibaeva, 1947). К. М. Патачаков, наряду с исследованиями истории хакасов, занимался вопросами родового состава этноса и влиянием внешних общественных факторов на изменения традиционного уклада жизни. Можно отметить такие работы автора, как «Культура и быт хакасов в свете исторических связей с русским народом (XVIII-XIX вв.)» (Patachakov, 1958), «Очерки материальной культуры хакасов» (Patachakov, 1982).

C. А. Токарев рассматривает особенности пережитков родовых отношений в обществе (Tokarev, 1952).

Исследованием фольклора в советский период занимались: В.Е. Майногашева, Н. П. Дыренкова, А. А. Кенель, А. Б. Соктоев.

В. Е. Майногашева (Mainogasheva, 1967) рассматривала особенности интерпретации героического эпоса Хакасии и раскрывала суть различных образов в эпосе. Автор создает обобщающий труд по поэтическому творчеству, показывает культурно-исторические связи тюркских народов в целом.

Музыкальным народным творчеством занимался А.А. Кенель, автор публиковал записи хакасских народных песен (Kenel, 1955). 
Под руководством А.Б. Соктоева выходит шестидесятитомник, посвященный памятникам фольклора народов Сибири и Дальнего Востока СССР, в том числе и народов, проживающих на территории Хакасии, из них четыре тома содержат хакасский фольклор.

Искусством этноса занимался исследователь С.А. Теплоухов в русле классификации культуры этноса (Teplouhov, 1995).

Историческое развитие этноса отражено в работах Л.П. Потапова. С 1960 г. сектор истории работает в тесном контакте с Объединенным институтом истории, филологии и философии СО РАН под руководством таких ученых, как А.П. Окладников, А.П. Деревянко, В.В. Алексеев, Н.Я. Гущин, И.И. Комогорцев, В. А. Ламин. Л.П. Потапов рассматривает основные этапы исторического развития хакасского этноса и систематизирует их, но отсутствует анализ этнокультурных явлений (Potapov, 1952).

Религиозной проблематикой занимался С. А. Токарев, рассматривая особенности религиозных убеждений, системы ценностей и верований, вопросы социологии религии (Tokarev, 1958). Автором изучается генезис религии, то есть корни возникновения религиозных убеждений хакасов, их хронологическая трансформация и факторы, влияющие на ее хронологические изменения.

Отраслью физической антропологии занимались такие ученые, как А.И. Ярхо (Yarho,1928), В.П. Алексеев (Alekseev, 1960), Г.Ф. Дебец (Debets, 1948), А.Р. Ким (Kim, 1984), Г. Л. Хить.

Важными исследованиями в сфере этнографии хакасского народа принадлежат Л.Р. Кызласову (Kyzlasov, 1960). Сфера деятельности ученого обширна и многогранна. В начале своей научной деятельности он занимался археологией, раскрывая и культурные связи. Поднимал ученый и вопросы истории искусств. В изучении древних периодов автором были уточнены роль культуры в неолитический период. В дальнейшем создается смежная область, синтезирующая в себе этнологию и архе- ологию, - этноархеология. В дальнейшем сфера интересов смещается в сторону изучения этнолингвистики и выявления происхождений хакасских топонимов и этнонимов и развития изучения эпиграфики.

В. Я. Бутанаев в начале исследовательской деятельности занимался социальноэкономическим проблемами Хакасии, позднее этнической культурой хакасов, принимал активное участие в экспедициях и полевых исследованиях, связанных с этносами Хакасии (Butanaev, 1983).

В.П. Кривоногов рассматривает этнические процессы, межэтнические браки, хакасов в русле социальной антропологии (Krivonogov, 1979).

Исследования, посвященные шорскому этносу, имеют обозначенные ранее модули. Здесь можно выделить таких исследователей, как В.И. Васильев, Г.Ф. Сысолятин, А.И. Чудоякова, С.В. Иванов, А.Р. Ким, В. М. Кимеев, Л. П. Потапов, З. П. Соколова, Э. Ф. Чиспияков.

Многие исследователи советского периода позднее, в конце XX - начале XXI в., также продолжали свою научную деятельность, расширяя и уточняя ее. Советский период раскрывает все аспекты изучения хакасского этноса, затрагивая как язык, культуру, родовой состав, так и данные физической антропологии. С развитием региональных центров изучения хакасского этноса происходит увеличение этнографических экспедиций, появляются собственные институты, направленные на сохранение и развитие культуры хакасского этноса. Можно отметить междисциплинарный характер в исследованиях авторов: в основном не делается акцент на изучение каких-либо одних культурных маркеров, они связаны между собой, в том числе и физическая антропология, расширяющая область исследования, которая связана с выявлением различных миграционных процессов на территории Республики Хакасия. История формирования этноса получает максимальное развитие в данный период. Развиваются археологические и этнографические исследования, в связи с чем уточняется и развивается изучение материальной 
культуры и фольклора. Данные фольклора являются таким же важным материалом бесписьменных культур, как и археологические исследования. Начинается развитие хакасской ономастики и топонимики.

\section{Обзор исследований}

этнокультурной динамики

в Республике Хакасия (1991-2005)

Обширные научные исследования хакасского этноса рубежа XX-XXI вв. представлены работами В.П. Кривоногова, Н. В. Аевой, В.И. Коробка, А.П. Боргояковой, Т.Г. Боргояковой, Е.К. Побызаковой, Л.В. Анжигановой, В.Н. Тугужековой, А. С. Логачевой,К. М. Торбостаева,А.С. Абдиной, В.Я. Бутанаева, И.И. Бутанаевой, С. Е. Яхонтова, И. Л. Кызласова и др.

В 1997 г. была опубликована монография этнографа и этносоциолога В.П. Кривоногова «Хакасы: Этнические процессы во второй половине XX века» (Krivonogov, 1997), раскрывающая проблемы современного этносоциального развития хакасского этноса. Автор в своей работе основывается на результатах собственных полевых исследований, датированных 1975-1993 гг., с привлечением статистических архивных сведений. В.П. Кривоногов подробно рассматривает особенности численности и территориального расселения хакасов, а также исследует современные этнические процессы хакасского этноса: этнической консолидации и межэтнической интеграции.

Проведением

экономикостатистического исследования актуального состояния и демографической динамики в Республике Хакасия занималась Н. В. Аева (Aeva, 2001). Исследователь подчеркивает обусловленность региональной специфики демографических процессов экономическими факторами, изменениями образа жизни, а также этническими особенностями региона. С.В. Москаленко в своей работе указывает на значение демографического вопроса при изучении этнических групп Южной Сибири, особенно в рамках исследования процессов современного развития этих этносов (Moskalenko, 2004).
Процессы консолидации в историческом прошлом этносов играют важную роль при анализе динамики численности предков современных народов Южной Сибири и выявлении базовых факторов, так или иначе оказавших влияние на демографические процессы, в том числе и хакасского этноса. Подобная исследовательская направленность прослеживается и в дальнейших работах отечественных ученых (Korobka, 2006; Bogatov, 2007).

А.П. Боргоякова поднимает проблему своеобразия языкового сознания хакасов (Borgoiakova, 2002a). В результате сравнительного анализа особенностей языкового сознания хакасов, русских и англичан Боргоякова фиксирует процессы языкового смещения у хакасов (в сторону русского языка) и, как следствие, трансформацию содержания образов сознания, мировоззрения хакасского этноса. Процессы утраты традиционного, национального знания хакасов происходят параллельно с формированием нового национального знания, новой этнического картиной мира. Т.Г. Боргоякова, Е. К. Побызакова занимаются исследованием социолингвистических процессов народов Южной Сибири (Borgoiakova, 2002b, Pobyzakova, 2005). Рассматривает механизм формирования мировоззрения этноca, основанного на единстве традиционных и современных представлений специфики межнационального, межэтнического, межкультурного взаимодействия, Л.В. Анжиганова (Anzhiganova, 1999).

Большое значение для изучения современных этнических процессов народов Южной Сибири имеют работы В.Н. Тугужековой (Tuguzhekova, 1998), в частности касающиеся определения практик адаптации хакасского этноса к современным трансформациям (Tuguzhekova, 2004). А. С. Логачева на основе материалов исследований, проводимых в 1990 - начале 2000х гг., в рамках исследовательской проблематики изучения социальных трансформаций, вызванных реформами 1990-х гг., выделяет основные изменения жизни хакасского этноса и особенности его развития в условиях современности (Logacheva, 2005). 
Остается актуальным вопрос этногенеза хакасского этноса, что подтверждает исследование К.М. Торбостаева, направленное на комплексное изучение происхождения хакасов в биологическом (основанном на данных антропологии), социальном (основанном на знании генезиса хакасских родоплеменных групп) и психологическом (основанном на этническом самосознании) аспектах (Torbostaev, 2003). Таким образом, исследователь делает попытки выявления генетических связей современного хакасского этноса с современными этносами Саяно-Алтайского региона, а также определения преемственности хакасского этноса с древним населением Хакасии. В исследовании А.С. Абдиной рассматриваются этногенетические вопросы генезиса хакасского этноса (Abdina, 2000).

В.Я. Бутанаев исследует особенности родового состава этнических групп СаяноАлтайского региона, в частности хакасского этноса (Butanaev, 1994). И. И. Бутанаева на основе анализа хакасского исторического фольклора определяет специфику исторического развития хакасского этноса и его основные этапы формирования (Butanaeva, 2000). К анализу исторической литературы в контексте изучения этнического названия хакасского этноса обращается С. Е. Яхонтов (Iakhontov, 1992). Вопросами этнического названия хакасов занимался и И. Л. Кызласов (Kyzlasov, 1992a; Kyzlasov, 1992b).

Исследовательский интерес к этническим процессам хакасского этноса конца $\mathrm{XX}$ - начала XXI в. прослеживается и в современных работах российских ученых. Так, Е.В. Самушкина исследует этнополитические процессы рубежа XX-XXI вв. и особенности формирования новой этнонациональной идеологии в Южной Сибири, в том числе на примере Республики Хакасия (Samushkina, 2008).

Таким образом, исследования рубежа XX-XXI вв. фиксируют процессы трансформации, вызванные политическими, экономическим событиями и затрагивающие разные сферы жизни хакасского народа. В связи с этим обостряется вопрос их этнического самосознания, этнической идентификации и самоидентификации. Большое значение обретают исследования специфики современных этнокультурных процессов и механизмов формирования этнического сознания, актуализируется интерес к историческому прошлому хакасского этноса.

\section{Обзор современных исследований этнокультурной динамики \\ в Республике Хакасия (2006-2021)}

Основные исследования в области этнокультурной динамики в Республике Хакасия проводятся учеными научноисследовательских центров Абакана, Красноярска, Новосибирска, Санкт-Петербурга и Томска. В последние двадцать лет вопрос этнокультурной динамики в Республике Хакасия приобретает особую значимость и актуальность среди ученых. Этнические процессы в республике изучаются учеными с различных сторон: с позиции истории, этнопсихологии, социологии, культурологии. Стоит заметить, что в первое десятилетие XXI в. внимание ученых было обращено, главным образом, к таким направлениям исследований, как история формирования хакасского этноса (В.Н. Асочакова, Н. А. Баранцева， В. Ю. Бутанаев， Г.В.Грошева, В.Н. Тугушекова, А.П. Шекшеев и др.), межэтническое взаимодействие хакасов с представителями других этнических групп, в особенности с русскими (Л.В. Анжиганова, Н.А. Баранцева, Т.В.Гусева, Е. А. Ерохина, В. П. Кривоногов, В.Г. Морогин, А.П. Шекшеев и др.), язык и религия хакасов (В.Н. Асочакова, М.В. Белозерова, В. Ю. Бутанаев, Г. В. Грошева, И.Р. Карамчакова, А.С. Логачева и др.), современное искусство Сибири (Е.П. Маточкин, Е. Ю. Павлова) (Nevol'ko, 2011). В 2010-х гг. данные направления продолжают оставаться в центре внимания ученых, однако приоритетным становится теперь их рассмотрение в контексте современных процессов, связанных с глобализацией и трансформацией этнической идентичности.

Все исследования этнокультурной динамики в Республике Хакасия в той или иной мере связаны с этнической идентич- 
ностью коренных народов, которая в свою очередь анализируется с позиции отдельных маркеров этнической культуры - семьи, языка, духовной и художественной культуры. Особое внимание учеными уделяется анализу межэтнических отношений и миграционных процессов, протекающих в Республике Хакасия.

Необходимо подчеркнуть, что этническая идентичность населения этой республики носит не простой, а сложный характер. Поэтому следует обратить внимание на теоретические работы, связанные с исследованием этнокультурных форм сложных идентичностей (Zamaraeva, Koptseva, 2020). Также в теоретическом аспекте важно формирование этнокультурных идентичностей посредством произведений искусства (Avdeeva, Degtyarenko, Koptseva, 2020).

Собственно проблеме этнической идентичности хакасов посвящает свое исследование Е.Е. Тиникова. В статье «Особенности этничности и межэтнических отношений в городской и сельской среде Хакасии» (Tinikova, 2020) автор обнаруживает влияние процессов урбанизации на этническую идентичность хакасов. На основе результатов социологического опроса Е.Е. Тиникова приходит к выводу о значимости этнической идентичности для городских и сельских жителей. Для городских жителей, по мнению исследователя, этническая идентичность имеет большее значение, чем для сельских. Согласно выводам автора, это связано с тем, что окружающая среда для хакасов (городских жителей) мыслится как агрессивная среда, актуализирующая в свою очередь значимость и ценность этнической идентичности в сознании народа.

Большое внимание учеными уделяется проблеме трансформации хакасской семьи. Трансформация ее материальной и духовной сфер анализируется И.Н. Трошкиной в статье «Этнокультурные особенности современной хакасской семьи» (Troshkina, 2019). Автор выделяет две сосуществующие тенденции, характеризующие хакасскую семью. Во-первых, это тенденция модернизации повседневной жизни семьи и ее культуры труда. В наибольшей степени модернизация затронула, согласно выводам И.Н. Трошкиной, именно культуру повседневности. Выявлена тенденция к приоритету иной одежды, новой мебели, бытовой техники, иной пищи. Влиянию данной тенденции подвергнуты и духовные основания хакасской семьи, главным образом язык. Для языковой картины мира хакасов, по замечанию автора, характерно расширение перечня новых слов. Наряду с модернизацией повседневной культуры хакасов И.Н. Трошкина обращается к анализу существующей практики ревитализации культурных символов, практики воспроизводства традиций и обычаев. Однако данная практика на фоне общей тенденции трансформации материальной и духовной сфер приобретает неотрадиционный вариант. В целом, автор видит уклон трансформации этнической культуры в сторону общероссийской. Автор пишет: «Общая площадка взаимодействия этнокультурных полей имеет крен в сторону общероссийской культуры на платформе традиций доминирующего этноса» (Troshkina, 2019: 190).

Проблема национально-смешанных браков среди хакасов исследуется В.П. Кривоноговым. В статье «Динамика национально-смешанной брачности у хакасов во второй половине XX - начале XXI в.» (Krivonogov, 2017) автор показывает зависимость уровня владения национальным языком и знаниями в области традиционной культуры от типа семьи. Хакасы, живущие в смешанных семьях, согласно выводам автора, лучше осваивают русский язык и русскоязычную культуру. В то же время многие национальные особенности у них ослаблены (не владеют хакасским языком, не знают отдельных элементов хакасской культуры). Данные процессы активизируют, по мнению автора, процессы межэтнической интеграции и ассимиляции.

Отдельным направлением исследований выступает этнолингвистика. Язык по-прежнему, по мнению ученых, остается важнейшей частью этнической идентичности, несмотря на общее снижение числа 
представителей этноса, владеющих родным языком. В частности, к таким выводам пришла А.В. Гусейнова в статье «Этнодемографические и языковые факторы хакасской этнической идентичности» (Guseinova, 2015). В статье автор выделяет язык как один из значимых этнокультурных маркеров наряду с практикой соблюдения традиций, знанием истории и культуры, уважением предков, дружбой с хакасами. Этой же точки зрения придерживаются Ю.В. Попков и Е.А. Тюгашев (Popkov, 2014), согласно которым снижение роли национального языка в жизни коренных народов не влечет за собой утрату этнической идентичности. Н.Т. Ултургашева в статье «Особенности современных исследований традиционной культуры народов Сибири» (Ulturgasheva, 2010) связывает процесс отчуждения от материнского языка и культуры с процессами языковой ассимиляции. Автор видит в возрождении национальной культуры «средство для самосохранения этноса, его этнической идентичности, национальной суверенности и культурной самобытности» (Ulturgasheva, 2010: 40).

В отношении религии наблюдается противоположная тенденция. В статье «Этноконфессиональная ситуация в Южной Сибири: социологический аспект исследования» Л.В. Анжиганова связывает утрату этнического самосознания с утратой религиозных традиций и появлением иных конфессий (Anzhiganova, 2016). Поэтому ревитализация религиозного сознания, возрождение именно традиционных верований хакасов имеют важное значение для укрепления этнической идентичности народа. Л.В. Анжиганова особую роль в данном процессе отводит идее возрождения национальной религии тюрко-монгольского мира - тенгрианства. Отмечая общий рост религиозных объединений различных конфессий на территории Республики Хакасия, автор связывает данное явление с тенденцией поиска религиозной идентификации и духовной жизни жителями Хакасии.

Еще одним направлением исследований этнокультурной динамики в Республике Хакасия является направление, связанное с миграционными процессами и межнациональными отношениями в республике. А.И. Дроздов в статье «Межнациональные отношения в Республике Хакасия в начале XXI в.: историко-статистический анализ» (Drozdov, Karachakova, 2019) приводит анализ статистических данных относительно этнического состава Республики Хакасия. В результате этого автор отмечает достаточно стабильный уровень численности доминирующих этносов в республике в начале XXI в. Миграционные процессы, по мысли автора, не играют какой-либо существенной роли в формировании населения Хакасии. Межнациональные отношения, согласно А.И. Дроздову, определяются «стремлением народов Хакасии к сохранению и развитию национальной самобытности в сочетании с потребностью в развитии единого этнокультурного пространства» (Drozdov, Karachakova, 2019: 198). В данном случае автор выделяет некоторую двойственность в сознании жителей республики. С одной стороны, народы стремятся сохранить и развить национальную самобытность. С другой - они испытывают потребность в развитии единого этнокультурного пространства. Таким образом, единое этнокультурное пространство должно включать в себя ряд отдельных самобытных культур. Многое в едином - таков посыл народов республики. Большую роль в возрождении национальной культуры А.И. Дроздов отводит национально-культурным организациям. Увеличение количества объединений за последнее десятилетие автор связывает с потребностью жителей республики обратиться к своим национальным корням, защитить права и интересы своей этнической группы.

Художественная культура Республики Хакасия также не осталась в стороне от общих процессов, связанных с трансформацией и глобализацией. Интерес для исследователей в данном направлении представляет как история развития национального искусства в Хакасии в целом, так и отдельные периоды его развития. Ю.К. Троякова в статье «Партийно-государственная политика по развитию профессионального изобрази- 
тельного искусства в Хакасии в 1965-1980х гг.» (Troyakova, 2012) рассматривает роль государственной и региональной политики в развитии профессионального искусства хакасских художников. Автор позитивно оценивает проводимую в республике политику, отмечая, что «выставки произведений профессиональных и самодеятельных художников, фотолюбителей, проведенные в 1965-1980-е гг, стали значительным событием в культурной жизни области и в целом продемонстрировали определенный уровень художественного мастерства и рост художественных кадров сибирской провинции» (Troyakova, 2012: 179).

О важности сохранения традиционной культуры в области декоративноприкладных искусств и ремесел пишет О.В. Киштеева в статье «Модель «Центра декоративно-прикладного искусства и художественных ремесел» как средство сохранения и развития художественных традиций этнической культуры Республики Хакасия» (Kishteeva, 2016). Автор видит в традиции способ поддержки порядка и стабильности, стратегию сохранения идентичности.

Другим актуальным направлением научных исследований в области художественной культуры Хакасии во втором десятилетии XXI в. становится обращение ученых к анализу традиционных религий, произведений декоративно-прикладного и изобразительного искусств, национальной литературы в контексте этнических процессов. Приоритетным в данных исследованиях выступает междисциплинарный подход. Религия и отдельные произведения национальной культуры рассматриваются как факторы формирования позитивной этнической и общероссийской идентичностей (Koptseva, Pimenova, Seredkina, 2013; Koptseva, Nevol'ko, Reznikova, 2013 и др.). Национальная художественная и духовная культуры, таким образом, наделяются функцией вторичного конструирова- ния первичных традиционных ценностей, представляющих основу для сохранения и поддержания этнической идентичности коренных народов в условиях динамично развивающегося современного мира.

\section{Заключение}

Рассмотренные периоды развития исследований этнических процессов в Республике Хакассия отражают запросы и возможности определенной эпохи. Период советского времени характеризуется сильной методологической ориентацией на марксистскую идеологию, но в то же время происходило социально-экономическое освоение огромной территории страны, что в свою очередь повлияло и на развитие изучения этнографических процессов. В советский период затрагиваются разные сферы функционирования этноса, такие как разные проявления культуры этноса, быт и хозяйство, родоплеменной состав и изменения, происходящие в нем, материальная культура этноса, изучение с применением археологических методов, методов социальной и физической антропологии. Современный период характеризуется наличием все тех же культурных маркеров, но появляются междисциплинарные области изучения этноса, где пересекаются, например, этническая и археологическая отрасли, процессы миграции изучают с точки зрения биологических, антропологических и этнолингвистических исследований. Важно отметить влияние на современную этническую идентификацию государственных и общемировых политических, культурных и социальноэкономических процессов. Отмечено сильное воздействие процессов глобализации, результатом которых является поворот к сохранению традиционной культуры. Происходит развитие конструирующих этническую идентичность факторов, таких как национальная культура, религиозные верования и др. 


\section{Список литературы}

Абдина, А.С. (2000). Группы крови у хакасов (гемотрансфузионные и этногенетические вопросы): автореф. дис. .... канд. мед. наук. Москва, 20 с.

Аева, Н.В. (2001). Статистический анализ демографического развития Республики Хакасия: дис. ... канд. эконом. наук. 169 с.

Алексеев, В.П. (1960). Краниология хакасов в связи с вопросами их происхождения // Труды Киргизской комплексной археолого-этнографической экспедиции, 4, 269-364.

Анжиганова, Л.В. (1999). Эволюция мировоззрения этноса: на примере хакасского народа: дис. ... д-ра филос. н. Москва, 450 с.

Анжиганова, Л.В. (2016). Этноконфессиональная ситуация в Южной Сибири: социологический аспект исследования // Международный научно-исследовательский журнал, 5 (47), 81-83.

Богатов, Е.А. (2007). Население Саяно-Алтая: историко-демографическое исследование. 1989-начало ХХІ в.: дис. ... канд. ист. наук. 217 с.

Боргоякова, А.П. (2002а). Национально-культурная специфика языкового сознания хакасов, русских и англичан: на материале ядра языкового сознания: дис. ... канд. фил. наук. 181 с.

Боргоякова, Т.Г. (2002b). Развитие социальных функций государственных тюркских языков Республик Южной Сибири: дис. на соискание ученой степени д. филол. н. 327 с.

Бутонаев, В.Я. (1983). Происхождение хакасов по данным этнонимики // Проблемы археологии и этнографии, 2, 68-73.

Бутонаев, В.Я. (1994). Происхождение хакасских родов и фамилий. Абакан, Лаборатория Этнографии НИС АГПИ, 93 с.

Бутанаева, И.И. (2000). Хакасский исторический фольклор: опыт историко-этнографического анализа: дис. ... канд. ист. наук. 200 с.

Дебец, Г.Ф. (1948). Палеоантропология СССР. Москва, руды института этнографии АН СССР, 392 с.

Доможаков, Н. Г. (1949). Описание кызыльского диалекта хакасского языка: автореф. дис. на соиск. учен. степ. канд. филол. наук. Абакан: Хакас. кн. изд-во, 11 с.

Дроздов, А.И., Карачакова, О.М. (2018). Деятельность национально-культурных центров Хакасии в 1990-е гг. // Genesis: исторические исследования, 12, 140-151.

Дроздов, А.И., Карачакова, О.М. (2019). Межнациональные отношения в Республике Хакасия в начале XXI в.: историко-статистический анализ // Genesis: исторические исследования, 12, 190199. DOI: $10.25136 / 2409-868 X .2019 .12 .31252$

Гусейнова, А.В. (2015). Этнодемографические и языковые факторы хакасской этнической идентичности // Приволжский научный вестник, 10 (50), 46-49.

Кенель, А.А. (1955). Народное музыкальное творчество хакасов. Абакан: Хакасское книжное изд-во, 142 с.

Ким, А.Р. (1984). Материалы к краниологии шорцев и кумандинцев // Западная Сибирь в эпоху средневековья, 180-195.

Киштеева, О.В. (2016). Модель «Центра декоративно-прикладного искусства и художественных ремесел» как средство сохранения и развития художественных традиций этнической культуры Республики Хакасия // Материалы IV Международной научно-практической конференции «Сохранение и развитие языков и культур коренных народов Сибири». Абакан, 296-301.

Копцева, Н.П., Неволько, Н.Н., Резникова, К.В. (2013). Формирование этнической культурной идентичности в современной России с помощью произведений национального искусства (на примере эвенкийского эпоса и декоративно-прикладного искусства) // Педагогика искусства, 1, 1-15.

Копцева, Н.П., Пименова, Н.Н., Середкина, Н.Н. (2013). Изучение декоративно-прикладного искусства и традиционных религий коренных малочисленных народов Севера как фактор формирования позитивной общероссийской культурной идентичности // Педагогика искусства, 2, 15-30.

Коробка, В.И. (2006). Статистическое исследование воспроизводства населения: на примере Республики Хакасия: дис. ... канд. экон. наук. 174 с. 
Кривоногов, В.П. (1979). К вопросу о современных этнических процессах у хакасов // Этногенез и этническая история тюрко-язычных народов Сибири и сопредельных территорий, 152-156.

Кривоногов, В.П. (1997). Хакасы в начале ХХІ века: Современные этнические процессы. Абакан: Хакасское книжное издательство, 144 с.

Кривоногов, В.П. (2017). Динамика национально-смешанной брачности у хакасов во второй половине XX - начале XXI в. // Научное обозрение Саяно-Алтая, 4 (20), 75-84.

Кузьмина, Е.Н., Рожнова, С.П., Третьякова, Ш.К. (2000). Памятники фольклора народов Сибири и Дальнего Востока: Аннотированный каталог опубликованных томов 1990-1998 г2. Институт филологии СО РАН. Новосибирск: Наука, 80 с.

Кызласов, Л.Р. (1960). Таштыкская эпоха в истории Хакасско-Минусинской котловины. (I в. до н. э. - V в. н. э.). Москва: из-во Московского университета, 197 р.

Кызласов, И.Л. (1992а). О самоназвании хакасов // Этнографическое обозрение, 2, 52-58.

Кызласов, И.Л. (1992b). Об этнонимах хакас и татар и слове хоорай (ответ оппонентам) // Этнографическое обозрение, 2, 69-75.

Логачева, А.С.(2005). Хакасия-восприятиенаселениемновыхусловийжизни//Социологические исследования, 9, 82-85.

Майногашева, В.Е. (1967). Об изучении героического эпоса хакасов // Изв. Сиб. отд-ния АН СССР. Сер. Обществ. науки, 1, 105-111.

Москаленко, С.В. (2004). Динамика численности и демографические предпосылки консолидации тюрок Южной Сибири во второй половине XIX - начале XX вв. // Этносы Сибири. Прошлое. Настоящее. Будущее. Krasnoyarsk, 121-130.

Патачаков, К.М. (1958). Культура и быт хакасов в свете исторических связей с русским народом (XVIII-XIX вв.). Абакан, 104 C.

Патачаков, К.М. (1982). Очерки материальной культуры хакасов. Абакан, 88 р.

Побызакова, Е.К. (2005). Экстралингвистические факторы функционирования хакасского языка // Развитие языков и культур коренных народов Сибири в условиях изменяющейся России: материаль Международной научной конференщии, 22-24 сентября 2005 года. Абакан: Изд-во ХГУ им. Н. Ф. Катанова, 77-82.

Попков, Ю.В. (2014). Этносоциальные процессы в Сибири: современные реалии и актуальные вопросы этнонациональной политики // Новые исследования Тувы, 3, 136-151.

Потапов, Л.П. (1952). Краткие очерки истории, этнографии хакасов» (XVII-\$5IX вв.). Абакан, 215 с.

Самушкина, Е.В. (2008). Символические и социо-нормативные аспекты современного этнополитического движения Республики Алтай, Республики Тыва, Республики Хакасия: (конец $X X$ - начало $X X I$ в.): дис. ... канд. ист. наук. 310 с.

Теплоухов, С.А. (1995). Опыт классификации древних металлических культур Минусинского края // Антология советской археологии (1917-1933), 1.

Тиникова, Е.Е. (2020). Особенности этничности и межэтнических отношений в городской и сельской среде Хакасии // Мониторинг общественного мнения: экономические и социальные перемены, 4, 533-548.

Токарев, С.А. (1958). Этнография народов СССР. Москва: Изд-во Моск. ун-та.

Токарев, С.А. (1952). Пережитки родовых отношений у хакасов в XIX веке // Сибирский этнографический сборник. Москва; Л.: Изд-во АН СССР, 108-141.

Торбостаев, К.М. (2003). Проблемы этногенеза хакасского народа: дис. ... канд. ист. наук. 159 с.

Трошкина, И.Н. (2019). Этнокультурные особенности современной хакасской семьи // Вестник Новосибирского государственного университета. Серия: История, филология, 18 (7), 187-199.

Троякова, Ю.К. (2012). Партийно-государственная политика по развитию профессионального изобразительного искусства в Хакасии в 1965-1980-х гг. // Исторические, философские, политические и юридические науки, культурология и искусствоведение. Вопросы теории и практики, 9-2 (23), 176-180.

Тугужекова, В.Н. (1998). Современное состояние хакасского этноса // Этносоциальные процессы в Сибири: тематический сб. Новосибирск, 2, 94-97. 
Тугужекова, В.Н. (2004). Влияние миграционного процесса на этническую структуру Республики Хакасия (к. XX - н. XXI вв.) // Актуальные проблемы истории Саяно-Алтая: науч. сб. молодых исследователей. Абакан, 5, 112-122.

Ултургашева, Н.Т. (2010). Особенности современных исследований традиционной культуры народов Сибири // Вестник Кемеровского государственного университета культуры и искусств, 13, 39-48.

Шибаева, Ю.А. (1947). Пережитки родового строя у хакасов. Рукопись дис. ... канд. ист. наук. Абакан, 253 р.

Ярхо, А.И. (1928). Физическое развитие населения Хакасского округа // Северная Азия, 4.

Яхонтов, С.Е. (1992). Слово хакас в исторической литературе // Этнографическое обозрение, 2 , $61-63$.

\section{References}

Abdina, A.S. (2000). Gruppy krovi u khakasov (gemotransfuzionnye i etnogeneticheskie voprosy) [Khakass blood groups (blood transfusion and ethnogenetic issues)]. Moscow, $20 \mathrm{s.}$

Aeva, N.V. (2001). Statisticheskii analiz demograficheskogo razvitiya Respubliki Khakasiya [Statistical analysis of the demographic development of the Republic of Khakassia]. $169 \mathrm{~s}$.

Alekseev, V.P. (1960). Kraniologiya hakasov v svyazi s voprosami ih proiskhozhdeniya [Kraniologiya khakassov in connection with the issues of their origin]. In Trudy Kirgizskoj kompleksnoj arheologoetnograficheskoj ekspedicii, 4, 269-364.

Anzhiganova, L.V. (1999). Evolyutsiya mirovozzreniya etnosa (na primere khakasskogo naroda) [Evolution of the ethnos worldview (on the example of the Khakass people)]. Moscow, $397 \mathrm{p}$.

Anzhiganova, L.V. (2016). Etnokonfessional'naya situaciya v Yuzhnoj Sibiri: sociologicheskij aspekt issledovaniya [Ethno-confessional situation in Southern Siberia: the sociological aspect of the study]. In Mezhdunarodnyj nauchno-issledovatel'skij zhurnal [International research journal], 5 (47), 81-83.

Avdeeva, Y.N., Degtyarenko, K.A., Koptseva, N.P. (2020). Compensatory role of symbolic mediators in constructing ethnocultural identity. In Journal of Siberian Federal University. Humanities and Social Sciences, 13(5), 702-715.

Bogatov, E.A. (2007). Naselenie Sayano-Altaya: istoriko-demograficheskoe issledovanie. 1989-nachalo XXI v. [The population of Sayan-Altai: a historical and demographic study. 1989-early XXI century]. $217 \mathrm{p}$.

Borgoiakova, A.P. (2002a). Natsional'no-kul'turnaya spetsifika yazykovogo soznaniya khakasov, russkikh $i$ anglichan (na materiale yadra yazykovogo soznaniya) [National and cultural specificity of the linguistic consciousness of the Khakassians, Russians and the British (based on the material of the core consciousness)]. $181 \mathrm{p}$.

Borgoiakova, T.G. (2002b). Razvitie sotsial'nykh funktsii gosudarstvennykh tyurkskikh yazykov respublik Yuzhnoi Sibiri [Development of social functions of the state Turkic languages of the republics of southern Siberia]. 327 p.

Butanaev, V. Ya. (1983). Proiskhozhdenie hakasov po dannym etnonimiki [The origin of the Khakass according to ethnonymy data]. In Problemy arheologii $i$ etnografiin [Istoricheskaya etnografiya: tradicii i sovremennost], 2, 68-73.

Butanaev, V. Ia. (1994). Proiskhozhdenie khakasskikh rodov i familii [The origin of the Khakass clans and surnames]. Abakan, Laboratoriya etnografii NIS AGPI, $93 \mathrm{s.}$

Butanaeva, I.I. (2000). Khakasskii istoricheskii fol'klor: Opyt istoriko-etnograficheskogo analiza [Khakass Historical Folklore: An Experience of Historical and Ethnographic Analysis]. $200 \mathrm{~s}$.

Debets, G.F. (1948). Paleoantropologiya SSSR [Paleontology of SSSR], Moscow, Trudy instituta etnografii, $392 \mathrm{p}$.

Domozhakov, N.G. (1949). Opisanie kyzyl'skogo dialekta hakasskogo yazyka [Description of the Kyzyl dialect of the Khakass language]. Hakasskoe knijnoe izdatelstvo, 11. 
Drozdov, A.I., Karachakova, O.M. (2018). Deyatel'nost' nacional'no-kul'turnyh centrov Hakasii v 1990-e gg. [Activities of the national-cultural centers of Khakassia in the 1990s]. In Genesis: istoricheskie issledovaniya [Genesis: Historical Research], 12, 140-151.

Drozdov, A.I., Karachakova, O.M. (2019). Mezhnacional'nye otnosheniya v Respublike Hakasiya v nachale XXI v.: istoriko-statisticheskij analiz [Interethnic relations in the Republic of Khakassia at the beginning of the XXI century: historical and statistical analysis]. In Genesis: istoricheskie issledovaniya [Genesis: Historical Research], 12, 190-199. DOI: 10.25136/2409-868X.2019.12.31252

Guseinova, A.V. (2015). Etnodemograficheskie i yazykovye faktory hakasskoj etnicheskoj identichnosti [Ethno-demographic and linguistic factors of the Khakass ethnic identity]. In Privolzhskij nauchnyj vestnik [Privolzhsky scientific bulletin], 10 (50), 46-49.

Iakhontov, S.E. (1992). Slovo «khakas» v istoricheskoi literature [The word «khakas» in historical literature]. In Etnograficheskoe obozrenie [The Ethnographic Review], 2, 61-63.

Kenel, A.A. (1955). Narodnoe muzykal'noe tvorchestvo hakasov [Khakass folk music]. Abakan, Hakasskoe knizhnoe izdatel'stvo, 142 p.

Kim, A.R. (1984). Materialy k kraniologii shorcev i kumandincev [Materials for the craniology of the Shors and Kumandins]. In Zapadnaya Sibir'v epohu srednevekov'ya, 180-195.

Kishteeva, O.V. (2016). Model' "Centra dekorativno-prikladnogo iskusstva i hudozhestvennyh remesel» kak sredstvo sohraneniya i razvitiya hudozhestvennyh tradicij etnicheskoj kul'tury Respubliki Hakasiya [The model of the «Center for arts and crafts and artistic crafts» as a means of preserving and developing the artistic traditions of the ethnic culture of the Republic of Khakassia]. In Materialy IV Mezhdunarodnoj nauchno-prakticheskoj konferencii «Sohranenie i razvitie yazykov i kul'tur korennyh narodov Sibiri» [Proc. $4^{\text {th }}$ International Scientific and Practical Conference]. Abakan, 296-301.

Koptseva, N.P., Nevol'ko, N.N., Reznikova, K.V. (2013). Formirovanie etnicheskoj kul'turnoj identichnosti v sovremennoj Rossii s pomoshch'yu proizvedenij nacional'nogo iskusstva (na primere Evenkijskogo eposa i dekorativno-prikladnogo iskusstva) [Formation of ethnic cultural identity in modern Russia by the works of national art (on the example of the Evenk epic and decorative and applied art). In Pedagogika iskusstva [Art pedagogy], 1, 1-15.

Koptseva, N.P., Pimenova, N.N., Seredkina, N.N. (2013). Izuchenie dekorativno-prikladnogo iskusstva i tradicionnyh religij korennyh malochislennyh narodov Severa kak faktor formirovaniya pozitivnoj obshcherossijskoj kul'turnoj identichnosti [Study of arts and crafts and traditional religions of the indigenous small-numbered peoples of the North as a factor in the formation of a positive all-Russian cultural identity]. In Pedagogika iskusstva [Art pedagogy], 2, 15-30.

Korobka, V.I. (2006). Statisticheskoe issledovanie vosproizvodstva naseleniya (na primere Respubliki Khakasiya) [Statistical study of population reproduction (on the example of the Republic of Khakassia)]. $174 \mathrm{p}$.

Krivonogov, V.P. (1979). K voprosu o sovremennyh etnicheskih processah u hakasov [On the question of modern ethnic processes among the Khakas]. In Etnogenez i etnicheskaya istoriya tyurko-yazychnyh narodov Sibiri i sopredel'nyh territorij, 152-156.

Krivonogov, V.P. (1997). Khakasy: Etnicheskie protsessy vo vtoroi polovine KhKh veka [Khakasy: Ethnic Processes in the Second Half of the 20 th Century]. Abakan, TOO «Tsentavr», $144 \mathrm{p}$.

Krivonogov, V.P. (2017). Dinamika nacional'no-smeshannoj brachnosti u hakasov vo vtoroj polovine XX - nachale XXI veka [The dynamics of nationally mixed marriage among the Khakass in the second half of the XX - early XXI century]. In Nauchnoe obozrenie Sayano-Altaya [Scientific review of Sayano-Altai], 4 (20), 75-84.

Kuz'mina, E.N., Rozhnova, S.P., Tret'yakova, Sh.K. (2000). Pamyatniki fol'klora narodov Sibiri i Dal'nego Vostoka: Annotirovannyj katalog opublikovannyh tomov 1990-1998 gg [Monuments of folklore of the peoples of Siberia and the Far East: Annotated catalog of published volumes 1990-1998]. Institut filologii SO RAN, $80 \mathrm{p}$.

Kyzlasov, L.R. (1960). Tashtykskaya epoha v istorii Hakassko-Minusinskoj kotloviny [The Tashtyk epoch in the history of the Khakassko-Minusinsk basin]. Moscow, Izdatelstvo Moskovskogo universiteta, $197 \mathrm{p}$. 
Kyzlasov, I.L. (1992a). O samonazvanii khakasov [About the self-name of the Khakass]. In Etnograficheskoe obozrenie [The Ethnographic Review], 2, 52-58.

Kyzlasov, I.L. (1992b). Ob etnonimakh «khakas» i «tatar» i slove «khoorai» [About the ethnonyms «Khakas» and «Tatars» and the word «khoorai»]. In Etnograficheskoe obozrenie [The Ethnographic Review], 2, 69-75.

Logacheva, A.S. (2005). Khakasiya - vospriyatie naseleniem novykh uslovii zhizni [Khakassia people's perception of new living conditions]. In Sotsiologicheskie issledovaniya [Sociological Research], $9,82-85$.

Mainogasheva, V.E. (1967). Ob izuchenii geroicheskogo eposa hakasov [On the study of the heroic epic of the Khakas]. In Izv. Sib. otd-nija AN SSSR. Seriya obshestvennie nauki, 1, 105-111.

Moskalenko, S.V. (2004). Dinamika chislennosti i demograficheskie predposylki konsolidatsii tyurok Yuzhnoi Sibiri vo vtoroi polovine XIX-nachale XX veka [Population dynamics and demographic prerequisites for the consolidation of the Turks of Southern Siberia in the second half of the $19^{\text {th }}-$ early $20^{\text {th }}$ centuries]. In Etnosy Sibiri. Proshloe. Nastoyashchee. Budushchee [To the Ethnoses of Siberia. Past. The present. Future]. Krasnoyarsk, 121-130.

Nevol'ko, N.N. (2011). Istoriograficheskij obzor nauchnoj literatury konca XIX - pervogo desyatiletiya XXI vv. po probleme etnicheskoj identifikacii hakasskogo etnosa [Historiographic review of scientific literature at the end of the XIX - the first decade of the XXI centuries on the problem of ethnic identification of the Khakass ethnos]. In Zhurnal Sibirskogo federal'nogo universiteta. Seriya: Gumanitarnye nauki [Journal of the Siberian Federal University. Series: Humanities], 4 (6), 823-836.

Patachakov, K.M. (1958). Kul'tura i byt hakasov v svete istoricheskih svyazej s russkim narodom $(X V I I I-X I X v v$.$) [Culture and life of the Khakass in the light of historical relations with the Russian people$ (XVIII-XIX centuries)]. Abakan, $104 \mathrm{p}$.

Patachakov, K.M. (1982). Ocherki material'noj kul'tury hakasov [Essays on the material culture of the Khakas]. Abakan, 88 p.

Pobyzakova, E.K. (2005). Ekstralingvisticheskie faktory funktsionirovaniya khakasskogo yazyka [Extra-linguistic factors of the functioning of the Khakass language]. In Materialy Mezhdunarodnoi nauchnoi konferentsii 22-24 sentyabrya 2005 goda [Materials from the International Conference September 22-24 2005]. Abakan, 77-82.

Popkov, Iu.V. (2014). Etnosocial'nye processy v Sibiri: sovremennye realii i aktual'nye voprosy etnonacional'noj politiki [Ethnosocial processes in Siberia: modern realities and topical issues of ethno-national policy]. In Novye issledovaniya Tuvy [New explorations of Tuva], 3, 136-151.

Potapov L.P. (1952). Kratkie ocherki istorii i etnografii hakasov (XVII-\$5IXvv.) [Brief essays on the history and ethnography of the Khakas (XVII-XIX centuries)], Abakan, 215.

Samushkina, E.V. (2008). Simvolicheskie i sotsio-normativnye aspekty sovremennogo etnopoliticheskogo dvizheniya Respubliki Altai, Respubliki Tyva, Respubliki Khakasiya: konets XX - nachalo XXI v [Symbolic and socio-normative aspects of the modern ethnopolitical movement of the Altai Republic, Tuva Republic, Khakassia Republic: late XX-early XXI century]. 310 p.

Shibaeva, Y.A. (1947). Perezhitki rodovogo stroya u hakasov $v$ sisteme rodstva i semejno-brachnyh otnoshenij [Remnants of the tribal system of the Khakas in the system of kinship and family-marriage relations]. Abakan, $253 \mathrm{p}$.

Teplouhov, S.A. (1995). Opyt klassifikacii drevnih metallicheskih kul'tur Minusinskogo kraya [Experience of classification of ancient metal cultures of the Minusinsk Region]. In Antologiya sovetskoj arheologii (1917-1933), 1.

Tinikova, E.E. (2020). Osobennosti etnichnosti i mezhetnicheskih otnoshenij v gorodskoj i sel'skoj srede Hakasii [Features of ethnicity and interethnic relations in the urban and rural environment of Khakassia]. In Monitoring obshchestvennogo mneniya: ekonomicheskie i social'nye peremeny [Public Opinion Monitoring: Economic and Social Change], 4, 533-548.

Tokarev, S.A. (1958). Etnografiya narodov SSSR [Ethnography of the USSR peoples]. Moscow: Izdatelstvo Moskovskogo universiteta. 
Tokarev S. A. (1952). Perezhitki rodovyh otnoshenij u hakasov v 19 v. [Remnants of clan relations among the Khakass in the $19^{\text {th }}$ century]. In Sibirskij jetnograficheskij sbornik, 108-141.

Torbostaev, K.M. (2003). Problemy etnogeneza khakasskogo naroda [Ethnogenesis problems of the Khakass people]. Ulan-Ude, $159 \mathrm{p}$.

Troshkina, I.N. (2019). Etnokul'turnye osobennosti sovremennoj Hakasskoj sem'I [Ethnocultural features of the modern Khakass family]. In Vestnik NGU. Seriya: Istoriya, filologiya [NSU Bulletin. Series: History, Philology], 18 (7), 187-199.

Troyakova, Yu.K. (2012). Partijno-gosudarstvennaya politika po razvitiyu professional'nogo izobrazitel'nogo iskusstva v Hakasii v 1965-1980-h gg. [Party-state policy for the development of professional fine arts in Khakassia in the 1965-1980]. In Istoricheskie, filosofskie, politicheskie i yuridicheskie nauki, kul'turologiya i iskusstvovedenie. Voprosy teorii i praktiki [Historical, philosophical, political and legal sciences, cultural studies and art history. Questions of theory and practice], 9-2 (23), 176-180.

Tuguzhekova, V.N. (1998). Sovremennoe sostoyanie khakasskogo etnosa [The current state of the Khakass ethnos]. In Etnosotsial'nye protsessy v Sibiri [Ethno-social processes in Siberia]. Novosibirsk, 2 , 94-97.

Tuguzhekova, V.N. (2004). Vliyanie migratsionnogo protsessa na etnicheskuyu strukturu Respubliki Khakasiya (k. XX - n. XXI vv.) [The influence of the migration process on the ethnic structure of the Republic of Khakassia (late XX-early XXI centuries)]. In Aktual'nye problemy istorii Sayano-Altaya [Actual problems of the history of the Sayan-Altai]. Abakan, 5, 112-122.

Ulturgasheva, N.T. (2010). Osobennosti sovremennyh issledovanij tradicionnoj kul'tury narodov Sibiri [Features of modern studies of the traditional culture of the peoples of Siberia]. In Vestnik Kemerovskogo gosudarstvennogo universiteta kul'tury i iskusstv [Bulletin of the Kemerovo State University of Culture and Arts], 13, 39-48.

Yarho, A.I. (1928). Fizicheskoe razvitie naseleniya Hakasskogo okruga [Physical development of the population of the Khakass district]. In Severnaya Aziya, 4.

Zamaraeva, Y.S., Koptseva, N.P. (2020) History of complex identity research. In Journal of Siberian Federal University. Humanities and Social Sciences, 13(7), 1216-1229. 